University of Nebraska - Lincoln

DigitalCommons@University of Nebraska - Lincoln

Faculty Publications from the Harold W. Manter Laboratory of Parasitology

$2-1980$

\title{
Parasite Population Regulation: Lethal and Sublethal Effects of Leptorhynchoides thecatus (Acanthocephala: Rhadinorhynchidae) on Hyalella azteca (Amphipoda)
}

Richard L. Uznanski

University of Notre Dame

Brent B. Nickol

University of Nebraska - Lincoln, bnickol1@unl.edu

Follow this and additional works at: https://digitalcommons.unl.edu/parasitologyfacpubs

Part of the Parasitology Commons

Uznanski, Richard L. and Nickol, Brent B., "Parasite Population Regulation: Lethal and Sublethal Effects of Leptorhynchoides thecatus (Acanthocephala: Rhadinorhynchidae) on Hyalella azteca (Amphipoda)" (1980). Faculty Publications from the Harold W. Manter Laboratory of Parasitology. 357.

https://digitalcommons.unl.edu/parasitologyfacpubs/357

This Article is brought to you for free and open access by the Parasitology, Harold W. Manter Laboratory of at DigitalCommons@University of Nebraska - Lincoln. It has been accepted for inclusion in Faculty Publications from the Harold W. Manter Laboratory of Parasitology by an authorized administrator of DigitalCommons@University of Nebraska - Lincoln. 


\title{
PARASITE POPULATION REGULATION: LETHAL AND SUBLETHAL EFFECTS OF LEPTORHYNCHOIDES THECATUS (ACANTHOCEPHALA: RHADINORHYNCHIDAE) ON HYALELLA AZTECA (AMPHIPODA)*
}

\author{
Richard L. Uznanski† and Brent B. Nickol \\ School of Life Sciences, University of Nebraska-Lincoln, Lincoln, Nebraska 68588
}

\begin{abstract}
The hypothesis that Leptorhynchoides thecatus populations are regulated by mortality of heavily infected intermediate hosts, Hyalella azteca, was examined experimentally. Mortality related to the infection process could not be demonstrated because no survivorship difference occurred between amphipod groups exposed to L. thecatus and unexposed control groups after $24 \mathrm{hr}$. Likewise, amphipod mortality could not be associated with infection intensity during this period. Amphipod mortality, growth, and infection intensity were monitored for 25 days after a 24 -hr exposure period. Cystacanths were infective to fish after 25 days. Survivorship of exposed amphipods was at least as great as that of unexposed controls. Infection intensity in exposed male survivors did not differ significantly from that in males that died during the study. Infection intensities in females and survivors of undetermined sex were significantly higher than in Hyallela that died. The effect of time on amphipod size (as indicated by head length) was significant for male survivors and all females, but not for males that died. No negative effect of infection intensity on growth was demonstrated, nor was there significant correlation between amphipod size and infection intensity for either sex of amphipod at any time during the 25-day experiment. No evidence of lethal effects or sublethal effects on growth was detected.
\end{abstract}

According to theoretical models, mortality of heavily infected hosts plays an important role in natural regulation of parasite populations (Anderson, 1978; Anderson and May, 1978; Crofton, 1971a, b; May, 1977; May and Anderson, 1978). Regulation through parasiteinduced host mortality is possible if 1) a link exists between infection intensity and host death; 2) host death prevents parasite reproduction; and 3) some hosts regularly acquire a lethal number of parasites under normal environmental conditions.

Van Cleave (1920) initially reported $\mathrm{Hy}$ allella azteca as intermediate host for Leptorhynchoides thecatus and no other arthropod since has been implicated in the life cycle. According to DeGiusti (1949), development of $L$. thecatus to an infective larva (cystacanth) requires approximately 30 days after the amphipod ingests eggs. Cystacanths attain a length of 2.5 to $3.5 \mathrm{~mm}$. Spaeth (1951) attributed mortality of laboratory grown $H$. $a z-$ teca to heavy infection with L. thecatus. Amphipods harboring L. thecatus cystacanths

Received for publication 7 June 1979.

* Manuscript preparation supported in part by grant AI 07030 from the National Institutes of Health, United States Public Health Service.

† Present address: Department of Biology, University of Notre Dame, Notre Dame, Indiana 46556. reproduced normally, although there was some evidence of reduced oocyte production (Spaeth, 1951).

The present study was undertaken to determine experimentally the lethal and sublethal effects of larval acanthocephalans, $L$. thecatus, on their hosts, H. azteca. Survivorship in exposed and unexposed amphipod groups was compared, and the relationship between parasite number and amphipod growth and survival was studied.

\section{MATERIALS AND METHODS}

Amphipods were collected from vegetation in reservoirs of Lancaster Co., Nebraska. Because $L$. thecatus does not occur in fish of this area (Samuel et al., 1976), amphipods were assumed uninfected. Only amphipods that passed through a $1.0-\mathrm{mm}$ mesh sieve and were retained by $0.710-\mathrm{mm}$ mesh were used for experimental purposes. Eggs of parasites were obtained from macerated female acanthocephalans that had been refrigerated several weeks in tap water. Uninfected fish were obtained in Lancaster Co., and maintained in amphipod free aquaria.

Amphipods were dissected in $0.25 \%$ saline on microscope slides. The head was severed while the amphipod was held with forceps. The posterior segments then were separated gently from the abdomen, allowing removal of the intact intestine and hepatic ceca. Parasites were counted with the aid of a compound microscope. The material was then washed into AFA, where it remained until further processing. Preserved specimens were stained overnight in acetocarmine prepared by diluting 1 
$\mathrm{ml}$ aqueous stock in $99 \mathrm{ml} 70 \%$ ethanol. Specimens were dehydrated in a series of alcohols, cleared in xylene, and mounted in Canada balsam.

Amphipod survivorship in the first $24 \mathrm{hr}$ after exposure was studied in 36 groups of 10 amphipods each to assess possible mortality related to the infection process. Each group was placed in a 5-ml beaker containing a small amount of algae and water. The beakers were assigned numbers randomly (1-36), and eggs from L. thecatus, collected at Rice Creek, Oswego Co., New York, were added to odd-numbered beakers. The beakers were placed in a humidified chamber consisting of a $34 \times 24 \times$ $9-\mathrm{cm}$ covered, plastic box containing moist paper towels, and placed under fluorescent illumination. Amphipods were removed and counted after $24 \mathrm{hr}$. All dead amphipods were examined immediately for parasites. Exposed survivors were placed in small jars containing algae and water, and examined for parasites during the next 11 days. Amphipods from three unexposed groups were examined and found to be free of $L$. thecatus.

A second experiment addressed lethal and sublethal effects during parasite development. Amphipods were sorted and randomly assigned to six exposure groups, A through $\mathrm{F}$, on day 0 . Each group was held in a small plastic cup containing water and a small amount of algae. Groups $\mathrm{A}, \mathrm{B}$, and $\mathrm{C}$ were exposed to eggs obtained from L. thecatus collected at Atkinson Lake, Holt Co., Nebraska. Groups D, E, and $F$ served as unexposed controls. All containers were placed under fluorescent illumination and aerated gently for $24 \mathrm{hr}$. Survival was assumed to be equal between exposed and unexposed amphipods during this period. On day 1 (1 DAE), amphipods were removed from exposure cups, washed to displace adherent eggs, and placed individually in vials containing water and algae. Each vial was covered with a randomly selected prenumbered cap which determined incubation period and replicate number, then placed in a randomly assigned position on a rack. Thus, each group was divided into eight incubation period classes, each comprising 12 amphipods. The rack was exposed to constant illumination from four fluorescent bulbs placed $76 \mathrm{~cm}$ from the rack. Algae in the vials provided food and oxygen.

Beginning 2 DAE, the amphipod in each vial was examined daily. An amphipod was considered dead if incapable of locomotion. Dead amphipods were dissected immediately. Empty positions on the rack were filled with empty vials to prevent accidental placement of an amphipod in an incorrect position. Beginning $5 \mathrm{DAE}$, and at 5-day intervals thereafter, all surviving amphipods in a selected incubation period class were dissected. All living amphipods in the four remaining incubation period classes were dissected 25 DAE. Some parasites recovered 25 DAE were fed to L. thecatus-free Lepomis cyanellus, and worms were recovered subsequently from the pyloric ceca, indicating cystacanth infectivity.

Amphipod head length, used to estimate size (Mathias, 1971; Strong, 1972), and infection intensity were recorded during dissection. In early infection stages, initial parasite counts were some-
TABLE I. Comparison of Leptorhynchoides thecatus recovery from a group of Hyallela azteca with high mortality and 17 groups with low mortality after 24-hr exposure to eggs.

\begin{tabular}{lcc}
\hline & $\begin{array}{c}\text { High } \\
\text { mortality } \\
\text { group }\end{array}$ & $\begin{array}{c}\text { Low } \\
\text { mortality } \\
\text { groups }\end{array}$ \\
\hline Mortality after $24 \mathrm{hr}$ & $80.0 \%$ & $1.8 \%$ \\
Parasites/amphipod (range) & $0-13$ & $0-21$ \\
Parasites/amphipod (mean) & 2.5 & 4.3 \\
Range of means & - & $0.7-9.6$ \\
\hline
\end{tabular}

times inaccurate because intestinal contents obscured the parasites. These counts were revised after examination of stained preparations. Approximately halfway through development, L. thecatus breaks free of the amphipod intestine, leaving behind a remnant of the acanthor membrane. This remnant was used to estimate infection intensity when the parasites were damaged in dissection. In some cases, no parasite count was possible owing to amphipod decomposition. Amphipod sex was determined during dissection.

A FORTRAN program employing the maximum likelihood method (Bliss and Fisher, 1953) was used to estimate parameters of the negative binomial distribution. The Statistical Analysis System (SAS) (Barr et al., 1976) was used for other statistical procedures.

\section{RESULTS}

In the 24-hr amphipod survivorship experiment, 11 of $180 \mathrm{H}$. azteca exposed to L. thecatus eggs and two unexposed amphipods died. Although this difference is statistically significant $\left(\chi^{2}=6.46, P<0.05\right)$, eight of the exposed, dead amphipods were from a single group. No more than one amphipod died in any other group. High mortality in a single group may have resulted from parasitism, in which case both maximum and mean infection intensities in groups with high mortality would be expected to be higher than in groups with low mortality, or it may have resulted from a random container effect. Neither mean nor maximum infection intensity was higher in the group with high mortality (Table I), and 13 groups with low mortality had higher mean infection intensities. Thus, amphipod mortality could not be attributed to infection by $L$. thecatus. Deletion of the group with exceptionally high mortality eliminates the survival difference between exposed and unexposed amphipods $\left(\chi^{2}=0.26\right.$, $P>0.5)$.

Occurrence of $L$. thecatus in laboratory-infected amphipods in the 25-day experiment is 


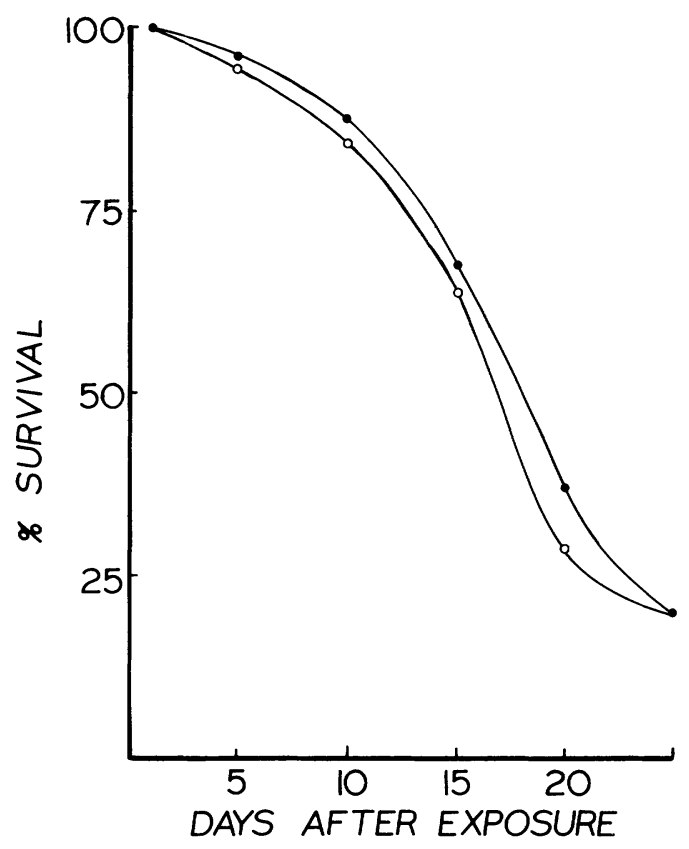

FIGURE 1. Survival of Hyalella azteca after exposure to Leptorhynchoides thecatus eggs in the laboratory. Open circles indicate unexposed amphipods; closed circles indicate exposed amphipods and common points.

presented in Table II. Observed frequency distributions conformed to negative binomials, and were significantly different from Poisson series.

Amphipod survivorship (corrected for previously dissected incubation period classes)

TABLE II. Frequency distribution statistics for Leptorhynchoides thecatus in experimentally infected Hyalella azteca.

\begin{tabular}{|c|c|c|c|c|}
\hline & \multicolumn{3}{|c|}{ Group } & \multirow[b]{2}{*}{ Combined } \\
\hline & $\mathbf{A}$ & B & $\mathrm{C}$ & \\
\hline Amphipods examined & 87 & 90 & 85 & 262 \\
\hline Amphipods infected & 63 & 86 & 71 & 220 \\
\hline Prevalence $(\%)$ & 72.4 & 95.5 & 83.5 & 83.9 \\
\hline Parasites/infection & 3.71 & 5.78 & 5.31 & 5.04 \\
\hline Parasites/amphipod (m) & 2.69 & 5.22 & 4.44 & 4.23 \\
\hline Variance of $m$ & 10.15 & 18.57 & 18.22 & 179.91 \\
\hline \multicolumn{5}{|c|}{ Negative binomial statistics } \\
\hline Estimated k & 0.98 & 2.39 & 1.31 & 1.31 \\
\hline$\chi^{2}$ Statistic & 0.74 & 4.05 & 6.23 & 10.11 \\
\hline$P\left(\chi^{2}\right)$ & 0.964 & 0.853 & 0.513 & 0.525 \\
\hline \multicolumn{5}{|l|}{ Poisson statistics } \\
\hline$\chi^{2}$ Statistic & 13.57 & 29.42 & 23.80 & 179.91 \\
\hline$P\left(\chi^{2}\right)$ & $0.019^{*}$ & $0.001^{*}$ & $0.001^{*}$ & $0.001^{*}$ \\
\hline
\end{tabular}

* Observed distribution significantly different from expected.
TABLE III. Comparison of numbers of parasites in dead and surviving Hyalella azteca experimentally exposed to Leptorhynchoides thecatus eggs.

\begin{tabular}{lccc}
\hline & $\begin{array}{c}\text { Number of } \\
\text { amphipods }\end{array}$ & \multicolumn{2}{c}{ Marasites/amphipod } \\
\cline { 3 - 4 } & & & Maximum \\
\hline Male amphipods & & 4.15 & 19 \\
$\quad$ Survivors & 54 & 4.58 & 18 \\
$\quad$ Dead & 52 & & \\
Female amphipods* & & 4.81 & 20 \\
$\quad$ Survivors & 80 & 3.35 & 15 \\
Dead & 67 & & \\
Undetermined sex amphipods* & & 9 \\
$\quad$ Survivors & 3 & 7.00 & 7 \\
$\quad$ Dead & 8 & 2.67 & 9 \\
\hline
\end{tabular}

* Significant difference (Wilcoxon two-sample test corrected for ties, $\alpha=0.05$ ) between dead and surviving amphipods.

over the 25-day development period is shown in Figure 1. Survival among exposed amphipods was at least as high as among unexposed amphipods. Amphipod mortality, higher than observed in natural populations (Cooper, 1965; Mathias, 1971) or group cultures in our laboratory, appeared related to bacterial infection, apparently exacerbated by experimental conditions.

The possible relationship between parasitism and host mortality was investigated further by comparing infection intensities in dead and surviving amphipods (Table III) by means of the Wilcoxon $U$-test (Sokal and Rohlf, 1969). Female amphipods and survivors of undetermined sex had significantly more parasites than did those which died. The difference was not significant for male amphipods.

The relationship between time and infection intensity on amphipod growth was examined by multiple regression (Table IV). Daily growth rates were significant for male survivors and all females. Competition between host and parasites for essential nutrients is expected to produce negative regression coefficients associated with infection intensity. Although not significantly different from zero, no estimated regression coefficient was negative. These results may indicate that larger amphipods ingested more eggs than did smaller amphipods. Correlation analysis (Table V) indicated no significant relationship between amphipod size and infection intensity 5 DAE and no general trend was apparent. The significant correlation coefficient ob- 
TABLE IV. Effect of time and infection intensity on growth (head length) in the laboratory of Hyalella azteca over 25 days. Observations in micrometers. Significance for $H_{0}: b_{i}=0$ is $\mathrm{P}>0.05$ unless otherwise indicated.

\begin{tabular}{|c|c|c|c|c|c|c|c|}
\hline $\begin{array}{l}\text { Amphipod } \\
\text { sex }\end{array}$ & $\begin{array}{c}\text { Mortality } \\
\text { status }\end{array}$ & $\begin{array}{c}\text { Exposure } \\
\text { history }\end{array}$ & $n$ & $\begin{array}{c}\text { (a) } \\
\text { Intercept }\end{array}$ & $\begin{array}{l}\left(\mathrm{b}_{1}\right) \\
\text { Time }\end{array}$ & $\begin{array}{c}\left(b_{2}\right) \\
\text { Intensity }\end{array}$ & $\begin{array}{c}\text { Coefficient } \\
\text { of } \\
\text { determination }\end{array}$ \\
\hline \multirow[t]{4}{*}{ Male } & Dead & Exposed & 47 & 555.98 & 3.20 & 3.03 & 0.076 \\
\hline & & Unexposed & 54 & 583.82 & 3.37 & - & 0.054 \\
\hline & Survivors & Exposed & 54 & 582.03 & $6.43 \dagger$ & 2.73 & 0.225 \\
\hline & & Unexposed & 53 & 608.23 & $4.04 *$ & - & 0.134 \\
\hline \multirow[t]{4}{*}{ Female } & Dead & Exposed & 66 & 558.60 & $3.84^{*}$ & 3.85 & 0.161 \\
\hline & & Unexposed & 100 & 509.82 & $7.25 \dagger$ & - & 0.286 \\
\hline & Survivors & Exposed & 80 & 553.39 & $7.21 \dagger$ & 1.71 & 0.391 \\
\hline & & Unexposed & 72 & 563.98 & $4.91 \dagger$ & - & 0.196 \\
\hline
\end{tabular}

$* P<0.01$.

$+P<0.001$.

served for mixed sexes 25 DAE may be spurious, having been generated by combining two groups, neither of which produced significant coefficients independently. In any event, there is no evidence suggesting retarded growth in $H$. azteca infected with $L$. thecatus.

\section{DISCUSSION}

Parasites often have been implicated in host mortality through either direct effects or increased vulnerability to predation. Crofton (1971a, b), Anderson (1978), and Anderson and May (1978) formally included parasite induced host mortality in definitions of parasitism and incorporated these definitions in models of host-parasite systems. Translation of the definitions into mathematical formality has required assumption that host mortality occurs often enough to regulate both host and parasite populations. The gap between occasional death of hosts with abnormally heavy infections and parasite induced host mortality

TABLE V. Correlation ( $\mathrm{r}$ ) between Hyalella azteca head length and number of Leptorhynchoides thecatus during parasite development.

\begin{tabular}{|c|c|c|c|c|c|c|}
\hline \multirow{3}{*}{$\begin{array}{c}\text { Days } \\
\text { after } \\
\text { expo- } \\
\text { sure }\end{array}$} & \multicolumn{6}{|c|}{ Amphipod sex } \\
\hline & \multicolumn{2}{|c|}{ Males } & \multicolumn{2}{|c|}{ Females } & \multicolumn{2}{|c|}{ Mixed } \\
\hline & $n$ & $r$ & $n$ & $r$ & $n$ & $r$ \\
\hline 5 & 10 & 0.037 & 22 & -0.023 & 32 & -0.077 \\
\hline 10 & 14 & 0.159 & 19 & 0.307 & 33 & 0.227 \\
\hline 15 & 13 & 0.009 & 13 & -0.307 & 26 & -0.232 \\
\hline 20 & 5 & 0.237 & 10 & 0.089 & 15 & 0.211 \\
\hline 25 & 12 & 0.330 & 16 & 0.429 & 28 & $0.375^{*}$ \\
\hline
\end{tabular}

* Statistical significance at $5 \%$ level for $\mathrm{H}_{0}: r=0$. as a regular event is a large one which should be crossed cautiously.

Much of the evidence invoked to support the theoretical models is inadequate in one or more respects. Distributions resembling truncated, negative binomials can be generated if egg hatching is inhibited by previously hatched parasites, or if hosts can avoid heavy concentrations of parasites. Thus, Crofton (1971a) and Lester (1977) did not clearly establish the link between parasitism and host death. For many species of parasite, transmission, and continuation of the life cycle requires predation on intermediate hosts by the definitive host. Crofton (1971a), Henricson (1977), Lester (1977), and Pennycuick (1971a, b) did not establish that host death necessarily terminated the parasite life cycle. In other cases, the parasite's reproduction occurred prior to host death (Massoud, 1974), or death of the host occurred after the parasites departed (Lanciani, 1975). Experimental studies that establish a link between parasitism and host death typically involve abnormal and highly susceptible hosts (Forrester, 1971; Hayes et al., 1973), or enormous parasite dosages in laboratory animals (Hunter and Leigh, 1961). In general, the workers cited made no claim that their observations were related to natural parasite population regulation. Additionally, Kennedy (1969) and McClelland and Bourns (1969) provided examples where parasitism may contribute to host longevity.

The present study supplements existing evidence (King, 1977; Vaughan and Coble, 1975) that parasites do not necessarily increase host mortality. DeGiusti (1949) reported that $0.4 \%$ and Esch et al. (1976) reported 
0.5 to $6.0 \%$ of Hyalella azteca were infected naturally with $L$. thecatus. Frequency distribution data were not presented, making direct comparisons between experimental and natural systems impossible. Prevalance, and perhaps mean infection intensity, was much higher in experimental amphipods (Table II) than in natural populations. High overall amphipod mortality rates suggest laboratory amphipods were in stressful environments. Nonetheless, exposure to L. thecatus eggs produced no demonstrable amphipod mortality in the laboratory (Fig. 1). The number of parasites was not associated with host mortality in initial stages of infection (Table I) or during parasite development (Table III). Spaeth (1951) reported contrary results in an experiment without replication and without reporting results for uninfected amphipods.

Our experimental protocol did not test indirect lethal effects mediated through competition or predation. Diversion of amphipod resources to the parasite's tissue did not significantly alter amphipod growth (Tables IV, V). Anecdotal evidence (Spaeth, 1951) suggests reduced oocyte production in infected female amphipods. Diversion to developing parasites of host resources normally allocated to reproduction is consistent with present data. Hyalella azteca apparently do not compete among themselves for food (Cooper, 1965), but predation by fish is thought to play a major role in amphipod population dynamics (Cooper, 1965; Strong, 1973; Van Dolah, 1978). Normal coloration and behavior allow H. azteca to hide from visually oriented fish (Strong, 1973). Prior to cystacanth formation, heavily infected $\mathrm{H}$. azteca are indistinguishable from their uninfected counterparts. Following cystacanth formation, selective predation by fish on infected amphipods would enhance transmission probabilities. Amphipod death is a necessary step in the $L$. thecatus life cycle. Based on available data, it seems unlikely that $L$. thecatus populations are regulated by death of heavily infected $H$. azteca.

Host-parasite population models based on the assumption that parasites kill heavily infected hosts should not be accepted without reservation. Empirical evidence offered to support the assumption is inconclusive and a body of contrary evidence exists.

\section{ACKNOWLEDGMENTS}

The authors wish to express appreciation to Dr. George H. Maxwell, II, Director, Rice Creek Biological Station, State University of New York, for arranging use of facilities; to Mr. David C. Ashley and Suzanne Uznanski for assistance in collecting; and to Mr. Ashley and Mr. Clarence A. Elkins for helpful comments on the manuscript.

\section{LITERATURE CITED}

ANDERSON, R. M. 1978. The regulation of host population growth by parasitic species. Parasitology 76: 119-157.

- AND R. M. MAY. 1978. Regulation of hostparasite population interactions. I. Regulatory processes. J Anim Ecol 47: 219-247.

BARR, A. J., J. H. Goodnight, J. P. SALL, AND J. T. HeLwig. 1976. A users guide to SAS.76. SAS Institute, Raleigh, North Carolina, 329 p.

Bliss, C. I., AND R. A. Fisher. 1953. Fitting the negative binomial distribution to biological data and a note on the efficient fitting of the negative binomial. Biometrics 9: 176-200.

CoOpER, W. E. 1965. Dynamics and production of a natural population of a fresh-water amphipod, Hyalella azteca. Ecol Monogr 35: 377-394.

Crofton, H. D. 1971a. A quantitative approach to parasitism. Parasitology 62: 179-193.

․ $1971 \mathrm{~b}$. A model of host-parasite relationships. Parasitology 63: 343-364.

DeGiusti, D. L. 1949. The life cycle of Leptorhynchoides thecatus (Linton), an acanthocephalan of fish. J Parasitol 35: 437-460.

EsCH, G. W., G. C. CAMPBELl, R. E. CONNERS, AND J. R. Coggins. 1976. Recruitment of helminth parasites by bluegills (Lepomis macrochirus) using a modified live box technique. Trans Am Fish Soc 105: 486-490.

ForRester, D. J. 1971. Heligmosomoides polygyrus (=Nematospiroides dubius) from wild rodents of Northern California: Natural infections, host specificity, and strain characteristics. J Parasitol 57: 498-503.

Hayes, T. J., J. Bailer, AND M. Mitrovic. 1973. The pattern of mortality in mice experimentally infected with Fasciola hepatica. Int J Parasitol 3: 665-669.

Henricson, J. 1977. The abundance and distribution of Diphyllobothrium dendriticum (Nitzsch) and D. ditremum (Creplin) in char, Salvelinus alpinus (L.) in Sweden. J Fish Biol 11: 231-248.

Hunter, G. C., AND L. C. Leigh. 1961. Studies on the resistance of rats to the nematode Nippostrongylus muris (Yokogawa, 1920). I. Dosage-mortality relationship. Parasitology 61: 347-351.

KENNEDY, C. R. 1969. Seasonal incidence and development of the cestode Caryophyllaeus laticeps (Pallas) in the River Avon. Parasitology 59: 783-794. 
KING, C. M. 1977. The effects of the nematode parasite Skrjabingylus nasicola on British weasels (Mustela nivalis). J Zool 182: 225-249.

LANCIANI, C. A. 1975. Parasite-induced alterations in host reproduction and survival. Ecology 56: 689-695.

LESTER, R. J. G. 1977. An estimate of the mortality in a population of Perca flavescens owing to the trematode Diplostomum adamsi. Can J Zool 55: 288-292.

Massoud, J. 1974. The effect of variation in miracidial exposure dose on laboratory infections of Ornithobilharzia turkestanicum in Lymnea gedrosiana. J Helminthol 48: 139-144.

Mathias, J. A. 1971. Energy flow and secondary production of the amphipods Hyalella azteca and Crangonyx richmondensis occidentalis in Marion Lake, British Columbia. J Fish Res Bd Can 28: 711-726.

MAY, R. M. 1977. Dynamical aspects of host-parasite associations: Crofton's model revisited. Parasitology 75: 259-276.

, AND R. M. ANDERSON. 1978. Regulation and stability of host-parasite population interactions. II. Destabilizing processes. J Anim Ecol 47: 249-267.

MCClelland, G., AND T. K. R. Bourns. 1969. Effects of Trichobilharzia ocellata on growth, reproduction, and survival of Lymnea stagnalis. Exp Parasitol 24: 137-146.

Pennycuick, L. 1971a. Seasonal variations in the parasite infections in a population of threespined sticklebacks, Gasterosteus aculeatus $\mathrm{L}$. Parasitology 63: 373-388. 1971b. Frequency distributions of parasites in a population of three-spined sticklebacks, Gasterosteus aculeatus L., with particular reference to the negative binomial distribution. Parasitology 63: 389-406.

Samuel, N., B. B. Nickol, and M. A. Mayes. 1976. Acanthocephala of Nebraska fishes. Am Midl Nat 96: 391-406.

Sokal, R. R., AND F. J. RohlF. 1969. Biometry. W. H. Freeman and Co., San Francisco, California, $776 \mathrm{p}$.

SPAETH, F. W. 1951. The influence of acanthocephalan parasites and radium emanations on the sexual characters of Hyalella (Crustacea: Amphipoda). J Morphol 88: 361-383.

STronG, D. R. 1972. Life history variation among populations of an amphipod (Hyalella azteca). Ecology 53: 1103-1111.

- 1973. Amphipod amplexus, the significance of ecotypic variation. Ecology 54: 13831388.

Van Cleave, H. J. 1920. Notes on the life cycle of two species of Acanthocephala from fresh water fishes. J Parasitol 6: 167-172.

VAN DOLAH, R. F. 1978. Factors regulating the distribution and population dynamics of the amphipod Gammarus palustris in an intertidal salt marsh community. Ecol Monogr 48: 191217.

VAUGHAN, G. E., AND D. W. CoBle. 1975. Sublethal effects of three ectoparasites on fish. J Fish Biol 7: 283-294. 